\title{
INCIDENCIA DE DOENÇAS E NECESSIDADE DE CONTROLE EM CULTIVO PROTEGIDO DE VIDEIRA ${ }^{1}$ \\ GERALDO CHAVARRIA ${ }^{2}$, HENRIQUE PESSOA DOS SANTOS ${ }^{3}$, OLAVO ROBERTO SÔNEGO ${ }^{4}$, GILMAR ARDUÍNO BETTIO MARODIN ${ }^{5}$, HOMERO BERGAMASCHI ${ }^{6}$, LOANA SILVEIRA CARDOSO $^{7}$
}

RESUMO - O cultivo protegido de videira no Brasil tem-se expandido, em área, visando principalmente à diminuição de danos por adversidades climáticas sobre a produção e a maturação das uvas. Entretanto, não se dispõe de informações sobre o microclima e as necessidades de controle fitossanitário que são impostas por essa tecnologia, as quais constituem os objetivos deste trabalho. O experimento foi instalado no ciclo 2005-2006, em Flores da Cunha-RS, em um vinhedo de 'Moscato Giallo', conduzido em "Y", com cobertura plástica impermeável $(160 \mu \mathrm{m})$, em 12 fileiras com $35 \mathrm{~m}$, deixando-se 5 fileiras sem cobertura (controle). Em ambas áreas, avaliou-se o microclima quanto à presença de água livre (registro visual), temperatura (T), umidade relativa (UR) do ar, radiação fotossinteticamente ativa (RFA) e velocidade do vento (VV) próximos ao dossel vegetativo e aos cachos. Na área coberta, foram aplicados fungicidas quando necessário, enquanto na área descoberta foram realizadas aplicações por calendário. Durante a floração e a maturação, avaliaram-se a incidência e a severidade de míldio (Plasmopara viticola), oídio (Uncinula necator), podridão-cinzentada-uva (Botrytis cinerea), podridão-da-uva-madura (Glomerella cingulata) e podridão ácida (leveduras imperfeitas e leveduras esporógenas). A cobertura plástica aumentou a temperatura diurna próxima ao dossel vegetativo, não influenciou na umidade relativa do ar, diminuiu a radiação fotossinteticamente ativa e a velocidade do vento e restringiu drasticamente a água livre sobre as folhas e cachos. Nessas condições, na área coberta, realizaram-se apenas duas aplicações para o controle do oídio, enquanto na área descoberta foram realizadas 17 aplicações para o controle de doenças fúngicas. Não houve incidência de doenças na avaliação realizada na floração, nos dois sistemas de cultivo; contudo, no período de maturação, houve decréscimos significativos de incidência de podridão ácida (-77,10\%) e a severidade de podridão-da-uva-madura (-89,47\%), podridão-cinzenta-da-uva (-57,56\%) e podridão ácida (-84,54\%) em função da cobertura plástica. De modo geral, as condições microclimáticas do cultivo protegido não permitiram o estabelecimento de míldio e diminuíram a incidência e severidade de podridões de cacho reduzindo as exigências e os custos com controle fitossanitário. Portanto, essa tecnologia pode apresentar-se como uma possibilidade de cultivo com menores impactos de contaminação para o ambiente, produtor e consumidor, desde que sejam consideradas as reduções de tratamentos fitossanitários. Isso fica evidente com os dados de acúmulo residual de fungicidas, que foi maior no cultivo protegido comparado ao convencional, de forma que o manejo fitossanitário deve ser diferenciado em relação ao cultivo convencional.

Termos para indexação: Vitis vinifera, plasticultura, doenças fúngicas, custo, sistema de produção, microclima.

\section{INCIDENCE OF DISEASES AND NEEDS OF CONTROL IN OVERHEAD COVERED GRAPES}

ABSTRACT - The plastic overhead cover (POC) of grapes is increasing in Brazilian vineyards aiming to reduce physical and biological damages. The objectives of this work had been to characterize the incidence and severity of diseases, and, consequently, the needs of control, as well as to evaluate the residues of fungicides in POC conditions. The experiment was installed in 2005/2006, in Flores da Cunha-RS, in a vineyard cv. Moscato Giallo, led in "Y Shape", with impermeable plastic covering $(160 \mu \mathrm{m})$, in 12 rows with $35 \mathrm{~m}$, being left 5 rows without covering (control). In both areas, the microclimate was evaluated with relationship to the presence of free water ( visual register ), temperature (T), relative humidity (UR) of the air, photosynthetically active radiation (PAR) and wind speed (WS) close to the leaves and clusters. In the covered area were only applied fungicides when necessary. In the control plants sprays were accomplished by calendar. Incidence and severity of downy mildew (Plasmopara viticola), powdery mildew (Uncinula necator), botrytis (Botrytis cinerea), rip rot (Glomerella cingulata) and sour rot (imperfect yeasts) were evaluated in each area during the flowering and ripening. The impermeable plastic covering increased the air temperature at the leaves level, and did not influenced the relative humidity of the air, but reduced the photosynthetically active radiation and the wind speed, and restricted the free water drastically on the leaves and clusters. The covered area needed only two sprays for the powdery mildew control, while in the discovered area 17 sprays were accomplished for control of fungal diseases. There were no incidence of diseases in the flowering evaluation in both treatments, however in the ripening period there was significant decrease of incidence of sour rot $(-77.10 \%)$ and severity of rip rot $(-89.47 \%)$, botrytis $(-57.56 \%)$ and sour rot (-84.54\%). The POC increased the temperature at the leaves and clusters levels, did not have influence upon the UR, reduced the PAR and wind speed and restricted the free water drastically on the leaves. The POC did not allow the downy mildew establishment and reduced the incidence and severity of clusters rottenness, reducing the needs and the costs with control disease, and promote the smaller impacts of contamination for the environment, producer and consumer than conventional system. As the residual accumulation of fungicides is higher in POC compared to the conventional system, the control disease should be differentiated.

Index Terms: Vitis vinifera, plasticulture, fungal diseases, cost, production system, microclimate.

(Trabalho 021-07). Recebido em: 18-01-2007. Aceito para publicação em : 24-08-2007.

Eng. Agr ${ }^{\circ}$ M. Sc. Doutorando UFRGS, Depto de Horticultura e Silvicultura, Porto Alegre-RS. geraldochavarria@hotmail.com, Bolsista: CNPq

2 Eng. Agr ${ }^{\circ}$ Dr. Pesquisador Embrapa Uva e Vinho, Cx. Postal 130, 95700-000, Bento Gonçalves-RS., henrique@cnpuv.embrapa.br

${ }^{3}$ Eng. Agr ${ }^{\circ}$ M. Sc. Pesquisador Embrapa Uva e Vinho, Cx. Postal 130, 95700-000, Bento Gonçalves-RS., sonego@cnpuv.embrapa.br

${ }^{4}$ Eng. Agr ${ }^{\circ}$ Professor Dr. Depto. de Horticultura, UFRGS, Cx. Postal 91540-000, Porto Alegre-RS. marodin@ufrgs.br

Eng. Agr ${ }^{\circ}$ Professor Dr. Depto. de Agrometeorologia, UfRGS, Cx. Postal 91540-000, Porto Alegre-RS. homerobe@ufrgs.br

${ }^{6}$ Eng. Agr ${ }^{\circ}$ Mestranda,UFRGS. Depto. de Agrometeorologia e Forrageiras, Cx. Postal 91540-000, Porto Alegre-RS. loanacar@yahoo.com.br 


\section{INTRODUÇÃO}

A viticultura mundial destinada à vinificação situa-se entre $30^{\circ}$ e $50^{\circ}$ de latitude norte e entre $30^{\circ}$ e $45^{\circ}$ de latitude sul, onde se apresentam climas de tipo temperado, mediterrâneo e com diferentes níveis de aridez (Tonietto \& Mandelli, 2003). Na região da Serra Gaúcha as condições climáticas podem apresentar-se desfavoráveis ao cultivo de videira em alguns aspectos. A freqüência e a distribuição de chuvas são elementos climáticos de grande importância neste processo produtivo, sendo que, nesta região Sul do Brasil, há uma série histórica pluviométrica com tendência ao excesso se comparada à regiões vitícolas tradicionais de outros países (Westphalen, 2000).

Devido a essas características climáticas, é observada com freqüência a realização de colheitas antecipadas, em comparação ao ponto ideal de maturação. Essa prática tem sido realizada com o intuito de evitar perdas ocasionadas por podridões dos frutos, porém resulta no comprometimento da qualidade enológica do mosto pela paralisação do processo de maturação (Tonietto \& Falcade, 2003).

No cultivo convencional de uvas viníferas no Rio Grande do Sul, são realizadas, em média, 14 pulverizações com fungicidas (Freire et al., 1992), das quais, 8 a 10 são efetuadas para o controle do míldio da videira (Plasmopara viticola) (Mendes, 2002). De forma corrente, o produtor realiza pulverizações semanais (método por calendário) com o intuito de garantir a sua produção, onde, em determinadas situações, pode não existir a real necessidade de aplicação de fungicidas.

Neste contexto, o ambiente protegido pode representar uma alternativa viável para minimizar problemas de maturação e manejo fitossanitário, principalmente por possibilitar modificações no microclima. Nessas condições, destaca-se a possibilidade de restrição da água livre sobre as folhas e frutos, que é o fator primário principal para desencadear o início das infecções fúngicas na videira (Grigoletti Júnior \& Sônego, 1993). O uso de cobertura plástica pode ser considerado o mais recente insumo agrícola, visando o incremento da produção e da qualidade, onde técnicas convencionais já foram esgotadas (Araújo \& Castellane, 1996). Entretanto, a utilização dessa tecnologia é incipiente em muitos países, sendo empregada principalmente no cultivo de uvas de mesa com o intuito de incremento da qualidade e conseqüente valor de venda (Shuck, 2002). Além disso, existem poucos estudos dos efeitos das mudanças microclimáticas ocasionados pela cobertura sobre a incidência e a severidade de doenças (Tivelli, 1998).

Por desconhecerem o manejo fitossanitário adequado no cultivo protegido, alguns produtores realizam aplicações recomendadas para o cultivo convencional como se estivessem cultivando em ambiente a céu aberto. Todavia deve ser salientado que o cultivo protegido se apresenta como um agrossistema diferenciado, onde a cobertura impõe uma barreira física à chuva e aos raios ultravioletas, os quais podem impedir a lavagem e/ou a degradação das moléculas de fungicidas. Essas influências sobre fungicidas são de extrema importância, considerando que os produtos podem apresentar um período residual diferenciado aos que se encontram nas condições de cultivo convencional.
Segundo Vida et al. (2004), existem alguns problemas ainda sem resposta para o cultivo protegido, incluindo a eficiência de agroquímicos, dosagens, intervalos de aplicação, fitotoxicidade, persistência e intervalo de segurança, os quais são essenciais para uma produção de qualidade, uma vez que estas informações só estão disponíveis para o cultivo convencional. Baseada nestas premissas, demonstra-se a necessidade de maiores estudos relacionados aos danos de diferentes patógenos, à necessidade de estratégias de controle e ao efeito dos agroquímicos nas condições microclimáticas proporcionadas pelo cultivo protegido.

Os objetivos do trabalho foram caracterizar os aspectos relacionados à incidência e à severidade de doenças, e, conseqüentemente, à necessidade de controle, e o monitoramento de resíduos de fungicidas em condições de cultivo protegido de videira.

\section{MATERIAL E MÉTODOS}

O experimento foi conduzido no ciclo 2005-2006 nos vinhedos de vinícola localizada em Flores da Cunha - RS, distrito de Mato Perso (latitude $29^{\circ} 06^{\prime}$ sul, longitude $51^{\circ} 20^{\prime}$ oeste e altitude de $541 \mathrm{~m}$ ), da cultivar 'Moscato Giallo' (clone VCR1), enxertada em porta-enxerto 'Kober 5BB' e com espaçamento de $3,0 \times 0,9 \mathrm{~m}$ (3.703 plantas/ha).

As plantas estavam conduzidas em "Y" com fileiras de 35 metros na direção nordeste-sudoeste, com poda mista, deixando varas de 6-8 gemas e esporões de duas gemas. O vinhedo foi dividido em duas partes. A primeira parte foi constituída por 12 fileiras cobertas na linha de cultivo com lonas plásticas trançadas de polipropileno transparentes, impermeabilizadas com polietileno de baixa densidade, com $160 \mu \mathrm{m}$ de espessura e largura de $2,65 \mathrm{~m}$. $\mathrm{Na}$ segunda parte, mantiveram-se cinco fileiras descobertas, cujas linhas centrais foram consideradas como plantas-controle.

$\mathrm{O}$ experimento foi conduzido em um delineamento experimental completamente casualizado, sendo identificadas 10 plantas marcadas aleatoriamente em cada área, onde foi considerada cada planta uma repetição. As doenças foram monitoradas visualmente quanto à incidência (presença ou ausência) e ao percentual de severidade de míldio (Plasmopara viticola), oídio (Uncinula necator), podridão-da-uva-madura (Glomerella cingulata), podridão-cinzenta-da-uva (Botrytis cinerea) e podridão ácida (ocasionada por leveduras imperfeitas e esporógenas). Essas avaliações foram efetuadas quando a maioria dos cachos se apresentava nos estádios fenológicos 65 e 81 (Lorenz et al., 1995), os quais representavam a plena floração e o início de maturação, respectivamente. Os dados foram submetidos à análise da variância, e as médias, comparadas pelo teste de Tukey, a $5 \%$ e $1 \%$ de probabilidade.

O microclima foi avaliado por meio de medições de temperatura, umidade relativa do ar, velocidade do vento e radiação fotossinteticamente ativa $(400-700 \mathrm{~nm})$, nas áreas, com e sem cobertura plástica. Todos os sensores da área coberta foram conectados a um multiplexador e este a um datalogger Campbell CR21X, enquanto no cultivo a céu aberto a um datalloger Campbell CR10. Ambos foram programados para realização de leitura a cada minuto e média desses dados a cada meia hora. Além disso, ao 
longo de todo o ciclo, foi realizado um monitoramento visual da presença ou ausência de água livre (gotas) sobre as folhas e cachos, na freqüência de duas vezes por semana, a partir da mudança de cor das bagas.

Ao longo de todo o ciclo vegetativo/produtivo, também foi registrado o número de aplicações de fungicidas nas áreas coberta e descoberta, assim como os produtos utilizados, objetivando caracterizar os contrastes na necessidade de controle fitossanitário.

Para o monitoramento dos efeitos da cobertura plástica sobre os resíduos de fungicidas, foram realizadas pulverizações com fungicida de princípio ativo captan $\left(125 \mathrm{~g} . \mathrm{L}^{-1}\right.$ de ingrediente ativo), em cachos previamente marcados, aleatoriamente, nas áreas coberta e descoberta, e realizadas coletas de amostras com e sem aplicação (cada amostra tendo a massa aproximada de $1 \mathrm{~kg}$ ), no dia da primeira aplicação, 2 dias após a primeira aplicação e 2; 7 e 14 dias após a segunda aplicação. Salienta-se que, para a segunda aplicação, foram utilizados cachos que receberam a primeira aplicação, simulando o efeito de reaplicações. As amostras (cada uma composta de quatro cachos) foram envoltas em papel alumínio e congeladas logo após as coletas. Posteriormente, foram analisadas pelo Laboratório de Análise de Resíduos de Pesticidas da Universidade Federal de Santa Maria, mediante método utilizando espectrometria de massa.

\section{RESULTADOS E DISCUSSÃO}

A cobertura plástica proporcionou uma diferenciação no microclima da videira em comparação ao cultivo a céu aberto. Na avaliação de todo o ciclo, as temperaturas médias tiveram incremento de $1^{\circ} \mathrm{C}$, enquanto as mínimas não tiveram diferença entre os dois sistemas de produção. Sendo assim, esse incremento médio deve-se as temperaturas máximas que tiveram médias de $31,8^{\circ} \mathrm{C}$ e $28,0^{\circ} \mathrm{C}$, respectivamente, para área coberta e descoberta (Tabela 1). Relativamente, estes aumentos de temperatura alcançaram percentuais de $+13,66 \%,+3,56 \%,+5,27 \%$, respectivamente para as máximas, mínimas e médias, no nível das folhas, e $+4,01 \%,+6,85 \% \mathrm{e}+2,97 \%$ próximo aos cachos, para as mesmas respectivas temperaturas, demonstrando que, no dossel vegetativo, possivelmente por se encontrar mais próximo da cobertura plástica, apresenta temperaturas máximas mais elevadas. O aumento das temperaturas máximas foi observado também por Ferreira et al. (2004), analisando vinhedo de 'Cabernet Sauvignon' com cobertura plástica nas linhas de cultivo. Segovia et al. (1997) atribuíram essa maior amplitude térmica no ambiente protegido devido à retenção de ar. Isso fica evidenciado nos resultados obtidos, pois a velocidade do vento foi atenuada em $88 \%$ junto ao dossel vegetativo das plantas cultivadas sob cobertura plástica (Tabela 1). Além da influência sobre a temperatura, a redução da velocidade do vento pode interferir, de maneira positiva, sobre a diminuição de incidência e severidade de doenças, pois o vento e a chuva são os principais fatores de dispersão de esporos de fungos (Aita, 1983).

A umidade relativa do ar não apresentou diferença entre as áreas coberta e descoberta, demonstrando que esse fator pode não ser determinante para a ocorrência ou ausência de doenças fúngicas, em áreas sob coberturas plásticas. Esse argumento, aparentemente, representa uma contradição, pois a literatura destaca que a umidade relativa do ar pode propiciar condições para o estabelecimento de doenças fúngicas (Pimpini, 1985). Essas condições, entretanto, estão relacionadas principalmente com a presença de água livre sobre as partes vegetativas e reprodutivas da planta, que foi nula durante todo o ciclo na área de cultivo protegido. Nesta área, a água livre ocorreu apenas na condensação na superfície interna dos plásticos da cobertura, e sem atingir a vegetação. Diversos modelos apontam que a duração do molhamento foliar, associada à temperatura, atua como fatores fundamentais para o processo de eficiência da infecção de doenças, como o míldio da videira (Lalancette et al., 1987). Com água livre disponível, vários processos relacionados às infecções das doenças, incluindo a liberação e a germinação de esporos, a penetração do tubo germinativo de fungos e a multiplicação de células de fitobactérias, ficam apenas dependentes da temperatura para seu estabelecimento (Agrios, 1997). Desse modo, considerando que, no cultivo protegido, o fator água não esteve presente, as condições de infecção das doenças fúngicas foram dificultadas. Apesar dessas evidências, no cultivo protegido, ainda pode ocorrer o acúmulo de água livre na superfície das folhas pela condensação do vapor de água da atmosfera ou, ainda, ser acumulada pela gutação, sendo esses fenômenos dependentes das condições da temperatura e da umidade relativa do ar (Vida et al., 2004). Entretanto, durante este ciclo em que foi realizada a experimentação, observou-se maior presença de água livre nos plásticos de cobertura, sendo muito baixa a freqüência de gutação. Considerando essas condições microclimáticas, destaca-se que, além da influência sobre o estabelecimento de doenças, podem também ocorrer alterações na eficácia do controle químico, pois esse é bastante influenciável pelos elementos climáticos, como temperatura, precipitação e umidade relativa do ar, principalmente no período de crescimento das brotações (Czermainski \& Sônego, 2004).

A radiação fotossinteticamente ativa $(400-700 \mathrm{~nm})$, incidente sobre o dossel vegetativo e os cachos, no ambiente coberto, diminuiu em $33 \%$ e $55 \%$, respectivamente, em relação à radiação incidente sobre o cultivo convencional a céu aberto. Rana et al. (2004) também observaram uma diminuição da radiação fotossinteticamente ativa, sendo atenuada em $17 \%$ em clarite e em 32\% em áreas cobertas com plástico impermeável e translúcido. Segundo Cañizares (1998), a redução da luminosidade favorece a incidência de oídio (Uncinula necator). Com isso, o sombreamento, associado às condições de restrição hídrica e elevação das temperaturas ocasionadas pelas coberturas plásticas, pode favorecer o surgimento dessa moléstia (Grigoletti Júnior \& Sônego, 1993).

Nas avaliações de incidência e severidade de doenças, realizadas no período de floração, não foram encontrados danos causados por doenças fúngicas nas áreas coberta e descoberta. A tendência à redução do uso de agroquímicos com a utilização do cultivo protegido, conforme abordada por Schuck (2002) e Santos (2005), foi comprovada, de forma que foram necessárias, na área coberta com o plástico impermeável translúcido, apenas duas aplicações em todo o ciclo, visando ao controle do oídio, 
enquanto foram realizadas 17 aplicações para o controle de doenças fúngicas na área convencional. Destaca-se, pelas condições microclimáticas da cobertura, que as duas aplicações para oídio foram feitas apenas nas manchas de ocorrência e não em toda a área, tendo-se total eficácia no controle. Além da diminuição dos gastos com fungicidas no cultivo protegido, tanto o produtor como o ambiente tiveram uma redução de 15 vezes do nível de exposição e contaminação por esses produtos.

Na maturação das uvas (estádio 81), também foram obtidos resultados significativos $(\mathrm{P}>0,001)$ na diminuição de incidência de podridões de cacho, atingindo em média $-64,35 \%$ (Tabela 2 ). Nessa redução de incidência de doenças, destacaram-se, principalmente a podridão-da-uva-madura $(-76,55 \%)$ e a podridão ácida $(-77,10 \%)$. As podridões de cacho consistem em um grande problema na viabilidade da produção vitícola por não existirem ainda medidas de controle inteiramente eficazes. Dessa forma, os resultados obtidos com a cobertura plástica apontam para uma possibilidade e sem ônus de contaminação, já que o controle é realizado pela mudança microclimática e não pelo emprego de agroquímicos.

Quanto à severidade de doenças, foi constatado um decréscimo significativo no grau de dano por podridão-da-uvamadura $(-89,47 \%)$, podridão-cinzenta-da-uva $(-57,56 \%)$ e podridão ácida (-84,54\%) (Tabela 2). Santos (2005) também observou vantagens do ambiente protegido, ao estudar o grau de severidade de doenças nas cultivares Cabernet Sauvignon, Moscato Giallo e Riesling Itálico. O autor observou apenas pequenos focos de infestação de oídio e podridão ácida no ambiente protegido, próximo ao ponto de colheita; entretanto, esses focos não comprometeram a qualidade enológica da uva. Isto é importante porque algumas doenças fúngicas, além de prejudicarem a produção propriamente dita, afetam a qualidade do vinho durante o processo de vinificação e no produto final, acentuando odores indesejáveis e acéticos. Uvas com Botrytis cinerea, por exemplo, contêm fenoloxidases e lacases que são enzimas responsáveis pela oxidação enzimática dos compostos fenólicos, produzindo a "casse oxidásica" e prejudicando a cor, o aroma e o sabor do vinho (Sônego et al., 2005).

Além dos efeitos benéficos sobre a produção, destaca-se que as folhas, no cultivo protegido, permaneceram biologicamente ativas por um período superior a 34 dias, comparativamente às plantas do cultivo convencional, sendo que a abscisão das folhas das plantas cobertas ocorreu devido à senescência, sem interferência de agentes externos. Em contrapartida, no cultivo convencional, a queda das folhas foi precoce e, possivelmente, relacionada ao aparecimento de doenças fúngicas ou a respostas de fitotoxidez aos agroquímicos aplicados. Dessa forma o processo fotossintético é favorecido nas áreas cobertas, atuando por um período superior e podendo refletir em um maior aporte de reservas para as plantas. De acordo com a literatura, o maior acúmulo de reservas de carbono pode contribuir para a fertilidade das gemas e, conseqüentemente, para o potencial produtivo da planta (Mullins et al., 1992).

Considerando a diminuição substancial da freqüência de aplicações no sistema protegido, diminui-se a possibilidade da criação de resistências dos patógenos aos produtos fitossanitários, que tem sido observada em sucessivas safras e que, em muitos casos, leva a um incremento no número de pulverizações e de princípios ativos utilizados (Grigoletti Júnior \& Sônego, 1993). Para comprovar essa eficácia dos fungicidas sob coberturas plásticas, destaca-se o acúmulo residual do princípio ativo captan que foi maior nos cachos cultivados sob cobertura plástica em $18,26 \%$, na avaliação realizada aos dois dias após a primeira aplicação e em 33,1\% e 27,52\%, nas avaliações realizadas aos dois e sete dias após a segunda aplicação, respectivamente (Figura 1). Esse efeito residual aumenta a ação dos produtos no controle fitossanitário, mas também pode influenciar na vinificação, já que as leveduras responsáveis pelo processo fermentativo se tratam também de fungos, assim como também na saúde dos consumidores de uvas de mesa consumidas in natura. O prolongamento da atividade dos produtos está, possivelmente, relacionado a dois fatores proporcionados com a alteração do microclima pela cobertura plástica: as diminuições do molhamento e da radiação solar. A chuva tem um efeito direto na lixiviação do produto aplicado e se esta não ocorre, principalmente lavando os cachos e as folhas, o efeito residual é prolongado. Esse efeito já foi observado em trigo e tomateiro, onde foi verificada a baixa persistência de mancozeb, sob condições de chuva induzida (Oliveira et al., 1998). Quanto menor o período entre a pulverização e as precipitações pluviais, menores serão as chances de absorção de produtos sistêmicos, reduzindose a respectiva eficácia (Hance \& Holly, 1990).

A diminuição da incidência de radiação solar ocasionada pela cobertura plástica também afeta a persistência dos fungicidas (Frank et al., 1987). Os plásticos utilizados nessas coberturas possuem aditivos químicos bloqueadores de raios ultravioletas, para que os mesmos aumentem sua durabilidade a campo (Venturin \& Santos, 2004). Entretanto, esse bloqueio impede também a degradação das moléculas de fungicidas, o que aumenta a persistência dos produtos nas condições de cultivo protegido (Figura 1).

Os resultados obtidos no cultivo protegido permitem sugerir uma grande diminuição na dosagem, na aplicação de fungicidas, sendo necessários outros experimentos com o objetivo de aferir as reais dosagens dos produtos. Isto é importante para que se tenha maior diminuição de custos e, principalmente, de resíduos em cultivos protegidos. Contudo, estas observações não podem restringir-se apenas à cultura da videira destinada à vinificação, mas podem ser extrapoladas para outros cultivos protegidos, tais como em uva de mesa, morango e hortaliças, salientando as conseqüências e as precauções que devem ser tomadas na utilização de agroquímicos em condições de cultivo protegido. 
TABELA 1- Dados médios de observações micrometerológicas conduzidas em "Y" sob cobertura plástica impermeável translúcida e a céu aberto. Flores da Cunha-RS, 2006.

de cultura. em vinhedos da cultivar Moscato Giallo

\begin{tabular}{lcc}
\hline & Área Coberta & Área Descoberta \\
\hline Média temp. máximas no dossel $\left({ }^{\circ} \mathrm{C}\right)$ & $31,8 \pm 6,3$ & $28,0 \pm 5,9$ \\
Média temp. médias no dossel $\left({ }^{\circ} \mathrm{C}\right)$ & $21,2 \pm 3,9$ & $20,2 \pm 5,3$ \\
Média temp. mínimas no dossel $\left({ }^{\circ} \mathrm{C}\right)$ & $14,7 \pm 3,6$ & $14,5 \pm 3,6$ \\
Média umidade relativa média no dossel $(\%)$ & $83,2 \pm 6,62$ & $82,6 \pm 7,43$ \\
Média umidade relativa média nos cachos $(\%)$ & $83,9 \pm 6,49$ & $84,6 \pm 7,84$ \\
Média radiação solar no dossel $\mathrm{MJ} / \mathrm{m}^{2} / \mathrm{dia}(400-700 \mathrm{~nm})$ & $5,4 \pm 1,92$ & $8,0 \pm 3,2$ \\
Média radiação solar nos cachos $\mathrm{MJ} / \mathrm{m}^{2} / \mathrm{dia}(400-700 \mathrm{~nm})$ & $1,32 \pm 1,11$ & $2,92 \pm 1,61$ \\
Média diária da velocidade do vento $\left(\mathrm{m} . \mathrm{s}^{-1}\right)$ & $0,09 \pm 0,20$ & $0,95 \pm 0,79$ \\
\hline *desvios-padrão relativos às observações efetuadas ao longo de todo o ciclo \\
de cultura.
\end{tabular}

TABELA 2 - Incidência e severidade de doenças em cachos da cultivar Moscato Giallo sob cobertura plástica impermeável translúcida (área coberta) e a céu aberto, no período de maturação. Flores da CunhaRS, 2006.

\begin{tabular}{lcccc}
\hline \multirow{2}{*}{\multicolumn{1}{c}{ Moléstia }} & \multicolumn{2}{c}{ Área Coberta $(\%)$} & \multicolumn{2}{c}{ Área Descoberta $(\%)$} \\
\cline { 2 - 5 } & Incidência & Severidade & Incidência & Severidade \\
\hline Míldio (Plasmopara viticola) & $0 \mathrm{aA}$ & $0 \mathrm{aA}$ & $0 \mathrm{aA}$ & $0 \mathrm{aA}$ \\
Oídio (Uncinula necator) & $0 \mathrm{aA}$ & $0 \mathrm{aA}$ & $0 \mathrm{aA}$ & $0 \mathrm{aA}$ \\
Podridão-da-uva-madura (Glomerella cingulata) & $0,87 \mathrm{aA}$ & $0,02 \mathrm{aA}$ & $3,71 \mathrm{aA}$ & $0,19 \mathrm{bA}$ \\
Podridão-cinzenta-da-uva (Botrytis cinerea) & $20,03 \mathrm{aA}$ & $1,01 \mathrm{bB}$ & $33,05 \mathrm{aA}$ & $2,38 \mathrm{aA}$ \\
Podridão ácida (Leveduras) & $10,29 \mathrm{bB}$ & $0,53 \mathrm{bB}$ & $44,95 \mathrm{aA}$ & $3,43 \mathrm{aA}$ \\
\hline
\end{tabular}

Média na linha seguidas de letras minúsculas e maiúsculas diferem entre si, ao grau de significância de 5 e $1 \%$, pelo teste de Tukey, respectivamente, separadamente para incidência e severidade de doenças.

${ }^{1}$ Percentuais médios de severidade de doenças obtidos dos cachos de 10 plantas em cada área.

\section{REFERÊNCIAS}

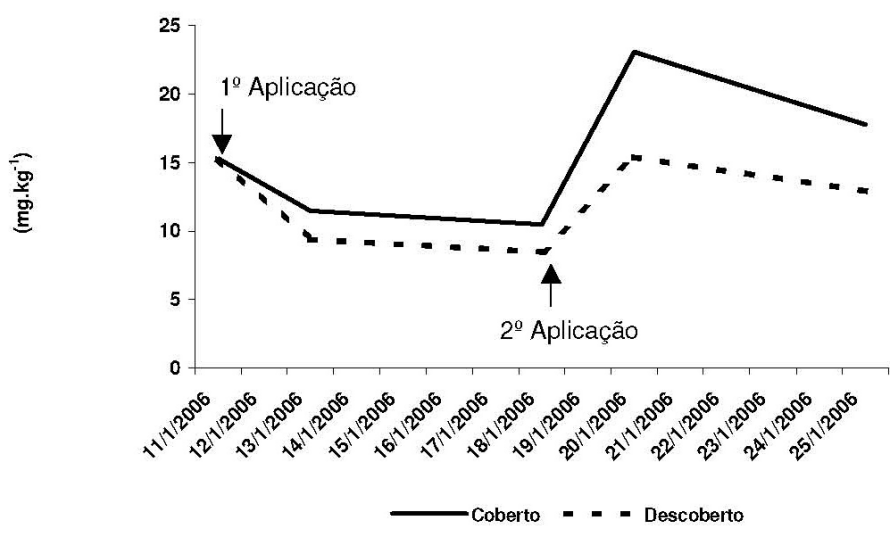

FIGURA 1 - Evolução temporal do teor de fungicida (princípio ativo captan) em uvas 'Moscato Giallo' conduzidas em "Y" sob cobertura plástica impermeável translúcida e a céu aberto. As aplicações foram realizadas com pulverizações até o escorrimento (125 g.L-1 i.a.). Flores da Cunha-RS, 2006.

\section{CONCLUSÕES}

1-A cobertura plástica impermeável apenas nas fileiras das plantas aumentou a temperatura próxima ao dossel vegetativo, não influenciou na umidade relativa do ar, diminuiu a radiação fotossinteticamente ativa e a velocidade do vento, e restringiu drasticamente a água livre sobre as folhas.

2-Nessas condições, o cultivo protegido não permitiu o estabelecimento de míldio e diminuiu a incidência e a severidade de podridões de cacho, devido à alteração microclimática.

3-O acúmulo residual de fungicidas é maior no cultivo protegido comparado ao convencional, de forma que o manejo fitossanitário deve ser diferenciado e restrito em relação ao cultivo convencional.
AGRIOS, G.N. Plant pathology. $4^{\text {th }}$ ed. London: Academic Press, 1997.

AITA, L. Informações sobre a coleta de alguns fungos fitopatogênicos por amostragem do ar. Fitopatologia Brasileira, Brasília, v.8, p.377-379, 1983.

ARAÚJO, J.A.C.; CASTELLANE, P.D. Recentes avanços da pesquisa agronômica na plasticultura brasileira. In: ARAUJO, J.A.C.; CASTELLANE, P.D. (Eds.) Dez anos de plasticultura na FCAV. Jaboticabal: FUNEP, 1996. p.67-68.

CAÑIZARES, K.A.L. A cultura do pepino. In: GOTO, R.; TIVELLI, S.W. (Eds.) Produção de hortaliças em ambiente protegido: condições subtropicais. Botucatu: FCA, UNESP, 1998. p.195-224.

CZERMAINSKI, A.B.C.; SÔNEGO, O.R. Influência das condições climáticas sobre a eficácia de fungicidas empregados para o controle do míldio em Vitis vinifera. Ciência Rural, Santa Maria, v.34, n.1, p.5-11, 2004.

FERREIRA, M.A.; PEDRO JÚNIOR, M.J.; SANTOS, A.O.; HERNANDES, J.L. Modificação parcial do cultivo da videira 'Cabernet Sauvignon' sobre diferentes porta-enxertos: Efeito sobre a produção e o teor de sólidos solúveis. Bragantia, Campinas, v.63, n.3, p.439-445, 2004.

FRANK R.; BRAUN H. E. ; RITCEY G. Disappearance of captan from field- and greenhouse-grown tomato fruit in relationship to time of harvest and amount of rainfall. Canadian Journal of Plant Science, Ottawa, v. 67, n.1, p. 355-357, 1987.

FREIRE, L.M.M.; FREIRE, J.M.; CALDART, V.Z. Transformação na estrutura produtiva dos viticultores da Serra Gaúcha: 19851991. Bento Gonçalves: EMBRAPA-CNPUV, 1992. 44p. (Documento, 7). 
GRIGOLETTI JÚNIOR, A.; SÔNEGO, O. R. Principais doenças fúngicas da videira no Brasil. Bento Gonçalves: EMBRAPACNPUV, 1993.36 p. (Comunicado técnico, 17).

HANCE, R.J.; HOLLY, K. Weed control handbook: principles. $8^{\text {th }}$ ed. London: BCPC Blackwell Scientific Publication, 1990.582p.

LALANCETE, N.; ELLIS, M.A.; MADDEN, L.V. Estimating infection efficency of Plasmopara viticola on grape. Plant Disease, St. Paul, v.71, p.981-983, 1987.

LORENZ, D.H.; EICHORN, K.W.; BLEHOLDER, H.; KLOSE, R.; MEIER, U.; WEBER, E. Phenological growth stages of grapevine (Vitis vinifera L.) - Codes and descriptions according to the extended BBCH scale. Australian Journal of Grape and Wine Research,Glen Osmond, v.1, p.100-103, 1995.

MENDES, C.S. Flutuação de inoculo no ar, desenvolvimento e validação de um sistema de previsão do míldio da videira. 2002. 123f. Dissertação (Mestrado) - Universidade de Passo Fundo, Passo Fundo, 2002.

MULLINS, M.G. Biology of the grapevine. Cambridge: Cambridge University, 1992.239p.

OLIVEIRA, S.H.F.; TÖFOLI, J.G.; DOMINGUES, R. J.; SANTOS, J.M.F. Ação da chuva sobre a sistemicidade, tenacidade e eficiência de fungicidas triazóis para o controle da ferrugem (Hemileia vastatrix) em cafeeiro. In: CONGRESSO BRASILEIRO DE PESQUISAS CAFEEIRAS, 1998, Poços de Caldas, 1998. Anais... p.183-184.

PIMPINI, F. L'umitá relative dell'aria in ambiente protetto. L'Itália Agrícola: serre e túnel. Roma, n.1, p.2-6, 1985.

RANA, G.; KATERJI, N.; INTRONA, M.; HAMMAMI, A. Microclimate and plant water relationship of the "overhead" table grape vineyard managed with three covering techniques. Scientia Horticulturae, Amsterdam, v.102, p.105-120, 2004.

SANTOS, H. P. Fruteiras de clima temperado em cultivo protegido: desafios e perspectivas em videira e macieira. In: SEMINÁRIO DE PESQUISA SOBRE FRUTEIRAS DE CLIMA TEMPERADO, 1., 2005 Bentos Gonçalves. Programa e resumos... Bento Gonçalves, RS: Embrapa Uva e Vinho, 2005. 44p. (Documentos, 52).
SEGOVIA, F. O.; ANDRIOLO, J.L.; BURIOL,A. G.; SCHNEIDER, F. M. Comparação do crescimento e desenvolvimento da alface (Lactuca sativa L.) no interior e no exterior de uma estufa de polietileno em Santa Maria, RS. Ciência Rural, Santa Maria, v.27, n.1, p.37-41, 1997.

SHUCK, E. Efeitos da plasticultura na melhoria da qualidade de frutas de clima temperado. In: ENFRUTE - ENCONTRO NACIONAL SOBRE FRUTICULTURADECLIMATEMPERADO, 5., 2002. Fraiburso, SC. Anais... p.203-213.

SÔNEGO, O.R.; GARRIDO, L. da R.; GRIGOLETTI JÚNIOR. Principais doenças fúngicas da videira no Sul do Brasil. Bento Gonçalves: EMBRAPA, 2005.32p. (Circular Técnica, 56).

TIVELLI, S.W. Manejo do ambiente em cultivo protegido. In: GOTO, R.; TIVELLI, S.W. (Org.). Produção de hortaliças em ambiente protegido: condições subtropicais. Botucatu: FCAV, UNESP, 1998. p.15-30.

TONIETTO, J.; FACALDE, I. Regiões vitivinícolas brasileiras: uvas para processamento. produção. Bento Gonçalves, RS: Embrapa Uvas e Vinhos, Brasília: Embrapa Informação Tecnológica, 2003. 134p. (Frutas do Brasil; 34).

TONIETTO, J.; MANDELLI, F. Clima: regiões vitivinícolas brasileiras, uvas para processamento. Bento Gonçalves, RS: Embrapa Uva e Vinho, Brasília: Embrapa Informação Tecnológica, 2003. 134p.; (Frutas do Brasil; 34).

VENTURIN, M.; SANTOS, H.P. Caracterização microclimática e respostas fisiológicas de uvas de mesa (Vitis labrusca e Vitis vinifera) cultivadas em ambiente protegido. In: CONGRESSO BRASILEIRO DE FRUTICULTURA, 18., 2004. Florianópolis. Anais... v.1, p.T0723. CD-ROM

VIDA, J.B.; ZAMBOLIM, L.; TESSMANN, D.J.; BRANDÃO FILHO, J.U.T.; VERZIGNASSI, J.R.; CAIXETA, M.P. Manejo de doenças de plantas em cultivo protegido. Fitopatologia Brasileira, Brasília, n.29, p.355-372. 2004.

WESTPHALEN, S.L. Caracterização das áreas bioclimáticas para o cultivo de Vitis vinifera L. nas regiões da Serra do Noroeste e Planalto do Estado do Rio Grande do Sul .Brasília: Embrapa Comunicação para Transferência de Tecnologia; Bento Gonçalves: Embrapa Uva e Vinho, 2000. 99p. 